\title{
Effect of Plant Extracts on Root-Knot Nematode Meloidogyne incognita Infecting Tomato
}

\author{
S.M. Vinodhini, T. Monisha, P. Praveen Arunachalam, \\ S. Rajshree, P. Vignesh, E.G. Ebenezar and N. Seenivasan*
}

Department of Plant Pathology, Agricultural College and Research Institute, Tamil Nadu Agricultural University, Madurai 625 104, Tamil Nadu, India

*Corresponding author

\section{A B S T R A C T}

\section{Keywords}

Tomato,

Meloidogyne

incognita, Plant

extracts,

Management

Article Info

Accepted:

04 May 2019

Available Online:

10 June 2019
The root-knot nematode, Meloidogyne incognita is a key pest on tomato cultivation throughout the world. Eco-friendly technique for the management of $M$. incognita on tomato is still lacking. Hence, studies were conducted to test the nematicidal potency of leaf extracts of asparagus, white hibiscus, jasmine and Ixora plants against $M$. incognita under in vitro and pot culture. Under in vitro condition juvenile mortality rate was higher (49.4-90.2\%) in asparagus treatment where as mortality rate was lower in Ixora treatment (8.2-35.4\%). Pot culture experiment on the efficacy of plant extract on $M$. incognita revealed that the infection of root-knot nematode in terms of number of galls/plant was lower in asparagus leaf extract treatment. In other treatments, the number of galls varied from 33-57 / plant where as in control 100 galls/plant. Asparagus treated plants were taller with long root system. It is concluded that leaf extracts of asparagus is having high nematotoxic potential against $M$. incognita which can be recommended to tomato growers for root-knot nematode control after testing under field situations.

\section{Introduction}

Tomato (Lycopersicon esculentum L) is the world's most important vegetable crop that plays important role to meet nutritional requirement of people throughout the world. The fruits of tomato are also used in the preparation of soup, salad, pickles, ketchup, puree and sauces. Ripe tomato fruit has high nutritive value being a good source of vitamin $\mathrm{A}, \mathrm{B}$ and $\mathrm{C}$, potassium and minerals. Rootknot nematode Meloidogyne incognita is a plant-parasitic nematode that causes serious damage on tomato in tropical and subtropical agriculture. Affected plants are often dwarfed, with small leaves. The infected tomato plants also express day wilt symptoms i.e. wilted appearance during day time and normal appearance during night time. The root-knot infected tomato express symptoms similar to nutrient deficiency. Tomato infested by $M$. incognita can lead to yield loss up to $80 \%$ (Nagachandrabose and Baidoo, 2017).

Management of nematodes in tomato can be achieved chiefly by chemical method. 
However, repeated application of chemical nematicides is needed to get desirable nematode control. Continuous application of chemical nematicide can lead to pollution problem and toxicity to non-target organism (Seenivasan, 2017).

In the recent years many bio-control agents were tested against plant parasitic nematodes including $M$. incognita on tomato. However non-availability of their commercial formulations leads to restrict their usage by farmers. Hence, the requirement of the day for $M$. incognita control in tomato should be ecofriendly and locally available. Among the various eco-friendly strategies available for nematode management, application of extracts of locally available plants is one of the thrust idea need to be exploited for field level application (Seenivasan, 2011).

The concept of plant origin bio-pesticides in modern agriculture has now attained wider applications than earlier. A large number of plants/plant parts or their products have been tested in-vitro for their nematicidal attributes revealed that extractives of several plants prepared in water or in organic solvents have been found effective against several economically important plant parasitic nematodes (Thoden and Korthals, 2011). However, little information is available on the presence of the bioactive products present in Asparagus, White hibiscus, Jasmine and Ixora effective against plant-parasitic nematodes. Hence, this study was conducted with the following objectives viz.,

1) To study the direct mortality of $M$. incognita when exposed to leaf extracts of Asparagus, White hibiscus, Jasmine, Ixora, and 2) To study the effect of amending the soil with leaf extracts of Asparagus, White hibiscus, Jasmine and Ixora on M. incognita infection on tomato roots under pot conditions.

\section{Materials and Methods}

\section{Culture of Meloidogyne incognita}

A population of Meloidogyne incognita used for in vitro and glass house studies, was originally isolated from the tomato roots at Fruit Orchard, Agricultural College and Research Institute, Tamil Nadu Agricultural University, Madurai, Tamil Nadu, India. A single egg mass of $M$. incognita was collected from the infected tomato roots, placed in a Petri dish containing sterile water and allowed to hatch for a week. The juveniles hatched out were multiplied on tomato $\mathrm{cv}$. Co 1 grown in pots (5 kg capacity) containing sterile red earth: sand: farmyard manure $(2: 2: 1)$ mixture in the glasshouse. After 8-10 weeks, eggs and juveniles were collected from the infected tomato roots by a modified $\mathrm{NaOCl}$ extraction method (Hussey and Barker, 1973; Seenivasan and Senthilnathan, 2018). The entire root system was dipped in water and soil was removed gently without detaching egg sacs. Eggs were extracted by vigorous shaking of infested roots in a $1 \%$ sodium hypochlorite solution for $3 \mathrm{~min}$. The resulting suspension was then passed through a range of deferent mesh-size sieves. The eggs were collected on a fine sieve (350 mesh) and washed in tap water to remove all traces of sodium hypochlorite before use. Hatched juveniles of $M$. incognita were obtained by placing the eggs in sterile distilled water for 5 days at room temperature. The freshly hatched juveniles (J2) were used for the laboratory and pot tests.

\section{Preparation of leaf extracts}

Five $g$ of leaves was taken in a conical flask and $80 \mathrm{ml}$ of methanol was added. It was kept in the shaker overnight at $40^{\circ} \mathrm{C}$ at $130 \mathrm{rpm}$, again $80 \mathrm{ml}$ of methanol was added and kept in shaker. This process was repeated for five times to get leaf extract concentrate. The 
prepared plant extracts were used for in vitro and pot tests.

Effect of plant extracts on second stage juveniles (J2) of Meloidogyne incognita

To determine the effect of various concentrations of plant extracts $(25 \%, 50 \%$ and $100 \%$ ) on mortality of $M$. incognita second stage juveniles (J2), $9 \mathrm{ml}$ of each plant extract concentrations was poured into small petri dishes to which $1 \mathrm{ml}$ suspension containing freshly hatched $\mathrm{J} 2$ containing 20 $\mathrm{J} 2 \mathrm{ml}^{-1}$ was added. One $\mathrm{ml}$ of juvenile suspension in nine $\mathrm{ml}$ of sterile distilled water served as control. Each treatment was replicated five times. For J2 mortality test, the number of dead juveniles were counted after $48 \mathrm{~h}$ exposure and expressed as per cent mortality. Nematode was considered dead if they did not move when probed with a fine needle.

Evaluation of plant extracts against $M$. incognita in tomato (Pot culture experiment)

The plant extracts of Asparagus, White hibiscus, Jasmine and Ixora were tested against $M$. incognita infesting tomato under glasshouse conditions. Pot culture experiment was conducted at the Department of Plant Pathology, Agricultural College and Research Institute, Madurai during February 2019 to April 2019. Tomato seed PKM1 obtained from Horticultural College and Research Institute, Periyakulam was used in this experiment. One month old tomato seedlings from nursery pots were carefully uprooted, washed thoroughly to remove the soil particles and transplanted @ one/pot in $15 \mathrm{~cm}$ diameter earthen pots containing steamsterilised pot mixture (Red soil: Sand: Farmyard manure; 3: 2: 1) and maintained in the glasshouse. At the time of sowing, the following treatments were applied to the soil in each pot and mixed thoroughly; T1 Asperagus extract; T2 - White Hibiscus extract; T3 - Jasmine extract; T4 - Ixora extract; and T5 - Untreated control. A completely randomized design was adopted with four replications for each treatment. Five days after sowing, freshly hatched, juveniles of $M$. incognita were inoculated in the root zone at $500 \mathrm{~J} 2 /$ pot. The plants were carefully uprooted after a month after inoculation and the observations on number of galls, shoot length and root length were made.

The data collected from both studies were analyzed and compared by $t$-test following Panse and Sukhatme (Panse and Sukhatme, 1954).

\section{Results and Discussion}

\section{Efficacy of Meloidogyne incognita in different plant extracts under in vitro conditions}

It was observed that all the tested concentrations of aqueous extracts $(25 \%, 50 \%$ and $100 \%$ or crude) viz., asparagus, white hibiscus, jasmine, Ixora caused mortality of M. incognita juveniles as compared with control. However, mortality rate significantly differed among tested plant extracts and even within their concentrations. Extract of asparagus was best among tested plant extracts which recorded $90.2 \%$ mortality while white hibiscus has mortality $74.3 \%$, jasmine recorded mortality of $50.4 \%$ and ixora has mortality rate of $35.4 \%$ in crude concentration (Figure 1).

At $50 \%$ concentration of the asparagus extract, the maximum mortality of juveniles $(79.1 \%)$ was recorded. It was followed by white hibiscus $(48.4 \%$ mortality), jasmine (35.6\% mortality) and Ixora (15.5\% mortality). In $25 \%$ concentration, the extract of asparagus has juvenile mortality of $49.4 \%$, 
white hibiscus recorded mortality of $23.5 \%$, jasmine recorded mortality of $14.7 \%$ and Ixora recorded $8.2 \%$ of mortality (Figure 1).

The results clearly evidenced that Asparagus leaf extract is the best for managing $M$. incognita than leaf extracts of white hibiscus, jasmine and ixora. The major bioactive constituents of Asparagus are a group of steroidal saponins. Other primary chemical constituents of Asparagus are essential oils, arginine, tyrosine, flavonoids and resin and tannin. The other bioactives principles are sarsasopogenin and shatavarin 1-4 which are present in leaves of Asparagus species. The nematicidal properties of root exudates of asparagus was first reported against the stubby root nematode, Trichodorus christiei ${ }^{[8]}$. They proved that a low molecular weight glycoside compound with aglycone is responsible $T$. christiei mortality. The asparagusic acid present in roots of asparagus was reported to have nematicidal property against several plant parasitic nematodes (Rohde and Jenkins, 1958). Earlier studies established that the compounds from asparagus root exudates and acid from asparagus root are responsible for nematode control. This work will be the first to establish the nematicidal properties of leaf extracts of asparagus against $M$. incognita. The presence of asparagusic acid was reported in seeds of asparagus plants (Takasugi et al., 1975). Results of our study also suggested that the leaf of asparagus might possesses glycoside like compound or asparagusic acid that might be studied further to prove this hypothesis.

Effect of plant extracts on galling of roots of tomato inoculated with Meloidogyne incognita under pot culture condition

The results revealed that lesser number of galls was produced by Meloidogyne incognita in the plants treated with Asparagus extract which was significant over the other treatments and the control (Figure 2). It was also observed that infectivity of root-knot nematode Meloidogyne incognita was not inhibited much with Ixora extract treatment. Earlier the root extracts of asparagus was evaluated against $M$. incognita on egg plant and results are in confirmatory with our findings (Izuogu et al, 2012). To our knowledge, this is the first report that evidenced the negative effect of leave extracts of asparagus on $M$. incognita infectivity on tomato. The bioactive compounds present in the leaf extracts of asparagus caused mortality of $M$. incognita that affected the infectivity on tomato plants. The results obtained in vitro studies supports this hypothesis (Table 1).

Table.1 Effect of different plant extracts on growth of tomato challenge inoculated with Meloidogyne incognita

\begin{tabular}{|c|c|c|c|c|}
\hline Treatments & $\begin{array}{c}\text { Shoot } \\
\text { length }(\mathbf{c m})\end{array}$ & $\begin{array}{c}\text { \% increase over } \\
\text { control }\end{array}$ & $\begin{array}{c}\text { Root length } \\
\text { (cm) }\end{array}$ & $\begin{array}{c}\text { \% increase over } \\
\text { control }\end{array}$ \\
\hline ASPARAGUS & 17.8 & 16.8 & 8.4 & 7.4 \\
\hline JASMINE & 10.3 & 9.3 & 5.7 & 4.7 \\
\hline WHITE & 13.7 & 12.7 & 6.3 & 5.3 \\
\hline HIBISCUS & & & & \\
\hline IXORA & 8.7 & 7.7 & 4.3 & 3.3 \\
\hline CONTROL & 6.9 & - & 4.1 & - \\
\hline CD at P=0.05 & 2.8 & - & 1.9 & - \\
\hline
\end{tabular}


Fig.1 Mortality rate of root knot nematode Meloidogyne incognita when exposed to different plant extracts under in-vitro condition

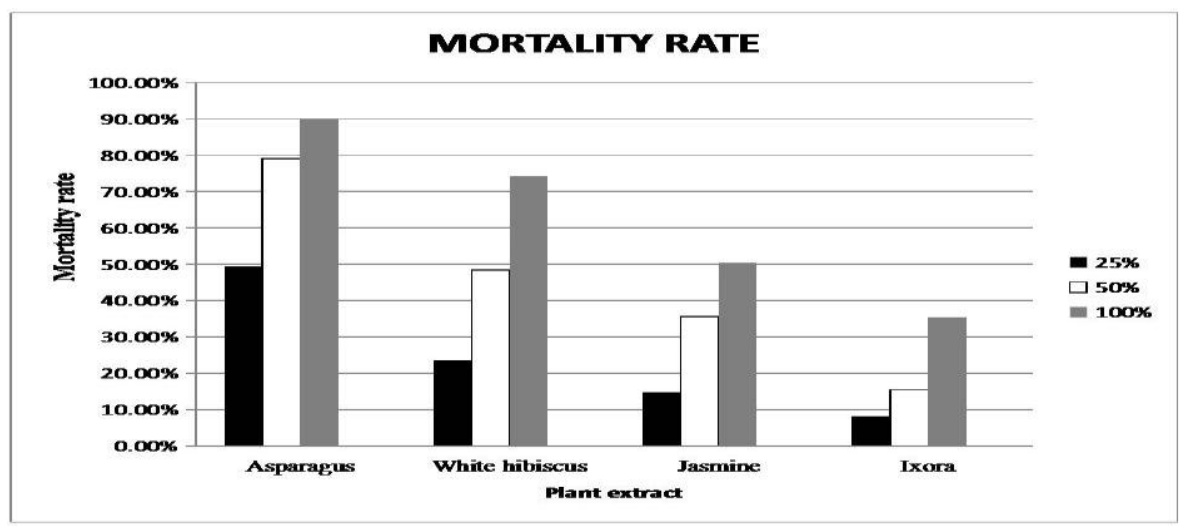

Fig.2 Infectivity of Meloidogyne incognita on tomato after treatment with plant extracts

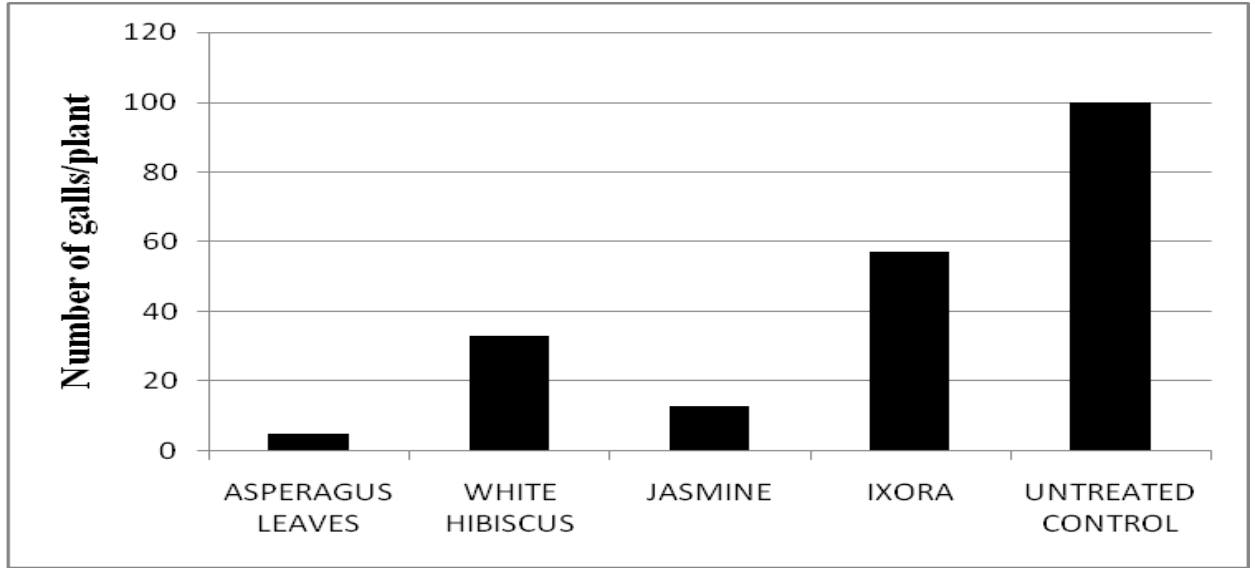

Fig.3 Galling pattern in asparagus treated and untreated tomato plant roots
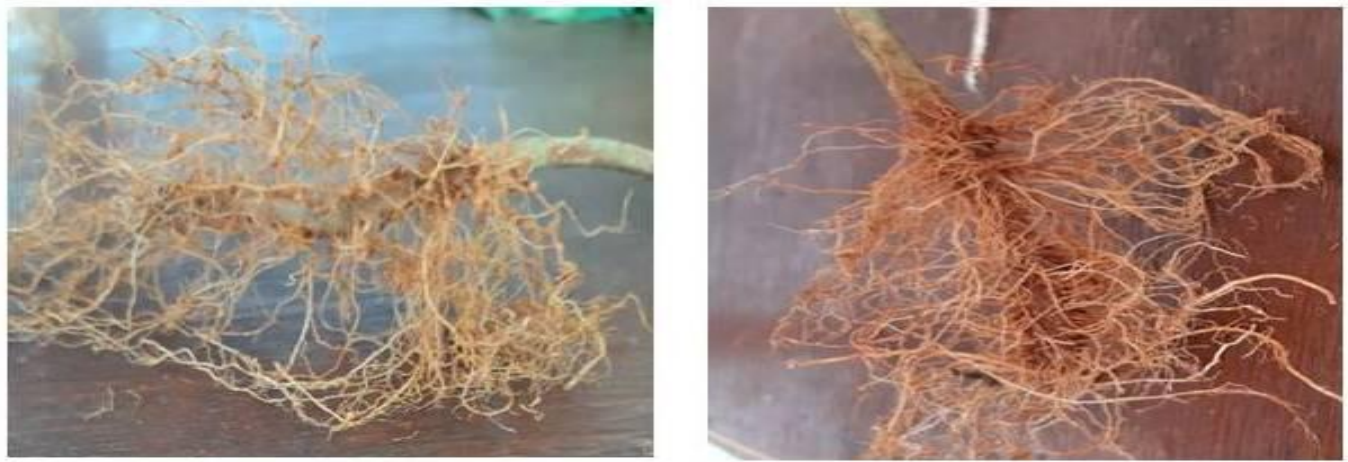

Untreated control

Asparagus extract treated plant 
The plants treated with Asparagus registered the maximum shoot length $(17.4 \mathrm{~cm})$ and root length $(8.7 \mathrm{~cm})$ (Figure 3$)$. The profound improvement in growth of tomato might be due to low $M$. incognita infectivity in asparagus treated plants. Similar results of improved growth due to $M$. incognita reduction were established earlier (Seenivasan, 2010).

From the findings of this research work, it can be recommended that soil application of methanol extracts of asparagus leaves can be followed by the tomato growers to manage root-knot nematode menace. It is a low cost technology i.e. the farmer itself can prepare asparagus leaf extracts as it is a common garden land weed plant. This technology can also become a replacement for the synthetic, dangerous and expensive chemical nematicide. However, further efficacy tests under field conditions are essential before adoption by farming community.

\section{References}

Hussey, R.S. and Barker, K.R. 1973. A comparison of methods of collecting inocula of Meloidogyne spp., including a new technique. Plant Disease Reporter. 57: 10251028.

Izuogu, N.B., Oyedunmade, E.E.A. and Usman, A.M. 2012. Toxicity of aqueous and powdered sparrow grass, Asparagus africanus to Meloidogyne incognita on egg plant. IJOARD. 37.

Nagachandrabose, S. and Baidoo, R. 2017. A Guide to Introductory Nematology. Nova
Science Publisher, New York, USA. pp. 217. Panse, V.G. and Sukhatme, P.V. 1954. Statistical Methods For Agricultural Workers. The Indian Council Of Agricultural Research; New Delhi..

Rohde, R.A. and Jenkins, W.R. 1958. Basis for resistance of Asparagus offidnalis var. altilis L. to the stubby-root nematode Trichodorus christiei Allen 1957. Bulletin of the Maryland Agricultural Experiment Station. A-97.

Seenivasan, N. 2010. Biointensive management of Meloidogyne incognita and Macrophomina phaseolina disease complex in medicinal coleus. Indian Journal of Plant Protection. 38(2): 186-192.

Seenivasan, N. 2011. Bioefficacy of anti-nemic plants against root-knot nematode in medicinal coleus. Journal of Ecofriendly Agriculture. 6: 92-96.

Seenivasan, N. 2017. Management of Radopholus similis and Helicotylenchus multicinctus in ratoon banana grown under high density planting systems. International Journal of Fruit Science. 17(1): 41-62.

Seenivasan, N. and Senthilnathan, S. 2018. Effect of humic acid on Meloidogyne incognita (Kofoid \& White) Chitwood infecting banana (Musa spp.). International journal of pest management. 64(2): 110-118

Takasugi, M., Yachida, Y., Anetai, M., Masamune, T. and Kegasawa, K. 1975. Identification of asparagusic acid as a nematicide occurring naturally in the roots of asparagus. Chemistry Letters. 4(1): 43-44.

Thoden, T.C. and Korthals, G.W. 2011. Organic amendments and their influences on plantparasitic and free-living nematodes: a promising method for nematode management. Nematology, 13: 133-153.

\section{How to cite this article:}

Vinodhini, S.M., T. Monisha, P. Praveen Arunachalam, S. Rajshree, P. Vignesh, E.G. Ebenezar and Seenivasan, N. 2019. Effect of Plant Extracts on Root-Knot Nematode Meloidogyne incognita Infecting Tomato. Int.J.Curr.Microbiol.App.Sci. 8(06): 373-378.

doi: https://doi.org/10.20546/ijcmas.2019.806.042 